\title{
Structural lineaments characterization in the central region of Araucarias Plateau: Preliminary analysis
}

Jacson Gosman Gomes de Lima ${ }^{1}$, Andrea Santos-Matos ${ }^{23}$, Suze Nei Pereira Guimarães ${ }^{4}$, Marga Eliz Pontelli ${ }^{5}$,

1 Instituto Federal de Santa Catarina - IFSC/SMO

2 Instituto Nacional de Pesquisas Espaciais - INPE/DIDGE/GEOMA - Grupo de Geomagnetismo

3 Universidade Federal do Pampa

${ }^{4}$ Observatório Nacional - ON/MCTIC - Laboratório de Geotermia

${ }^{5}$ Núcleo de Estudo Paleoambientais - NEPA/UNIOESTE

Copyright 2019, SBGf - Sociedade Brasileira de Geofísica

This paper was prepared for presentation during the $16^{\text {th }}$ International Congress of the Brazilian Geophysical Society held in Rio de Janeiro, Brazil, 19-22 August 2019.

Contents of this paper were reviewed by the Technical Committee of the $16^{\text {th }}$ International Congress of the Brazilian Geophysical Society and do not necessarily represent any position of the SBGf, its officers or members. Electronic reproduction or storage of any part of this paper for commercial purposes without the written consent of the Brazilian Geophysical Society is prohibited.

\section{Resumo}

The present work have as objective the characterization of structural lineaments, shown the relationship between the magnetic lineaments (deep structures), geomorphologic lineaments (shallow structures), fails/fractures and the drainage network. The study was carried in the Midwest region of Araucarias Plateau, west of Santa Catarina state, Brazil. Preliminary analysis suggest that structures mapped in the study area are oriented in accordance with the principal structure direction of Parana Basin, NE-SW, SW-NE and E-W. It was possible to observe that the main rivers in the study area are adjusted by magnetic and most-negative lineaments, suggesting that the structural influence was a conditioning factor in the drainage network organization, directing the main rivers.

\section{Introdução}

Por muito tempo os estudos geomorfológicos negligenciaram a influência tectônica na evolução do relevo brasileiro. No entanto, a partir da década de 90 torna-se consenso na ciência geomorfológica que mesmo no interior de placas tectônicas o relevo é modelado tanto pela ação de processos exógenos como endógenos (SAADI, 1998). Apesar dessa constatação, ainda hoje é preciso aprofundar o entendimento sobre o arcabouço estrutural, para a partir disso tentar entender como as estruturas tectônicas influenciam o relevo.

No Planalto das Araucárias, em seu setor central, ainda não se sabe qual a exata influência do arcabouço estrutural nas formas de relevo. Nessa unidade morfoescultural, trabalhos de cunho tectônico foram desenvolvidos, principalmente análises morfométricas, mostrando que o relevo sofreu influência de estruturas tectônicas regionais (LIMA e PONTELLI, 2013; FUJITA et al., 2017).

Ainda assim, é preciso aprofundar os conhecimentos, caracterizando o arcabouço estrutural, resultado que pode servir de base para estudos futuros, tanto a respeito da geologia quanto da geomorfologia regional.
Neste contexto, este trabalho apresenta resultados do mapeamento de lineamentos magnéticos na região central do Planalto das Araucárias, unidade morfoescultural localizada inteiramente no interior da Bacia do Paraná, onde adotou-se recorte espacial com $10956 \mathrm{~km}^{2}$ (figura 1).

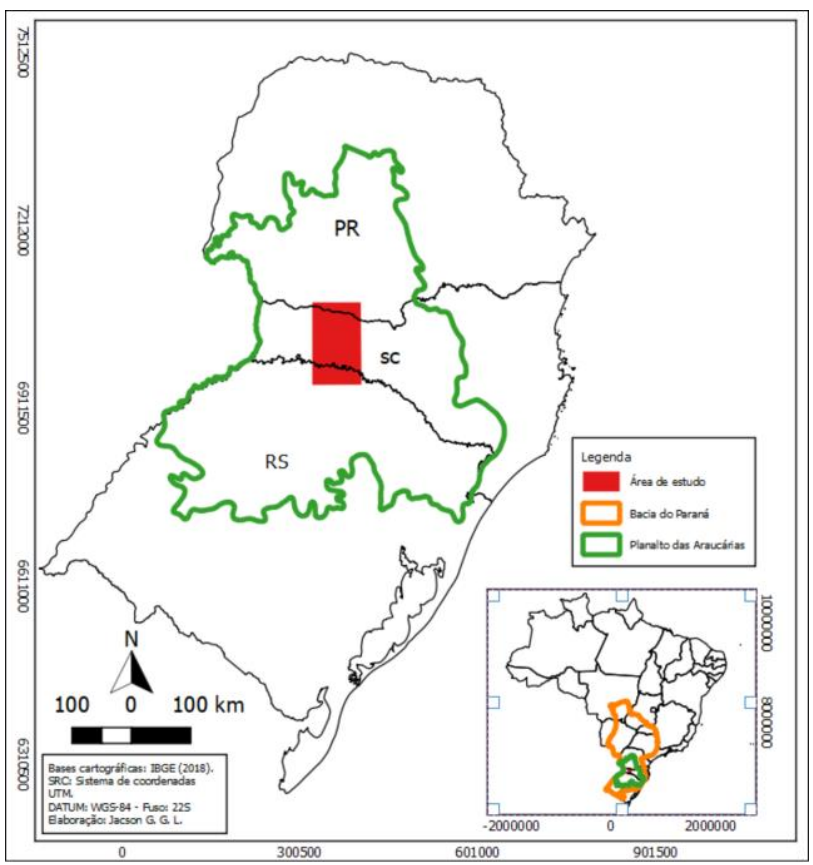

Figura 1. Localização da área de estudo.

Assim, o presente estudo tem como objetivo caracterizar os lineamentos estruturais da área de estudo de modo a contribuir com essa analise em detalhe, mostrando a relação entre os lineamentos magnéticos (estruturas profundas), obtidos por analise geofísica magnética, e os lineamentos geomorfológicos (estruturas superficiais) obtidos por meio de imagens de radar (SRTM-30m).

\section{Método}

Os dados aeromagnetométricos utilizados para a elaboração dos mapas de anomalias magnéticas apresentados neste trabalho, foram adquiridos junto a Agência Nacional de Petróleo e Gás - ANP. Tais dados são do projeto Rio Iguaçu (1980). O levantamento foi realizado com altura nominal de voo de $500 \mathrm{~m}$ e frequência de aquisição de $1 \mathrm{~s}$, no intervalo de $100 \mathrm{~m}$. As linhas de voo tiveram espaçamento de $2 \mathrm{~km}$, com direção 
$\mathrm{N}-\mathrm{S}$, e as linhas de controle espaçamento de $20 \mathrm{~km}$, com direção E-W.

Para processar esses dados foi utilizado o software Oasis Montajï, versão 8.4. da Geosoft. Este processamento envolveu inicialmente correções de aquisição como filtragem, nivelamento, micro nivelamento, correções de spikes, lag e posicionamento. Após esse processo iniciou-se a separação das fontes magnéticas nas medidas de campo geomagnético adquirido no aerolevantamento, como: parte principal (interior da Terra), que é calculada pelo modelo IGRF, parte diurna (exterior a Terra, advinda basicamente do Sol) que é monitorada durante a aquisição de dados e a parte crustal (anômala), que corresponde ao campo magnético advindo de rochas magnéticas na crosta. Sendo assim, o próximo passo foi gerar o grid do campo magnético anômalo (CMA) a partir do método da mínima curvatura em malha regular com células de $500 \mathrm{~m}$ (figura 2).

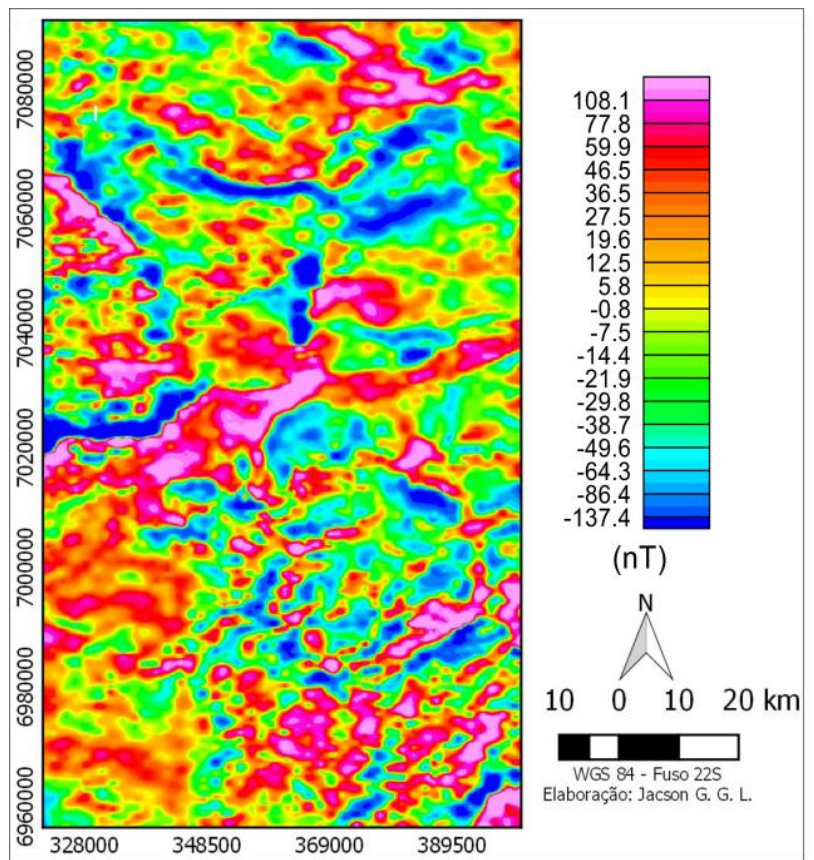

Figura 2. Mapa do campo magnético anômalo.

Posteriormente foram aplicadas técnicas geofísicas interpretativas de realce em anomalias magnéticas para delimitação dos lineamentos magnético, destacadas a seguir: derivada vertical (DV), derivada horizontal (DH) e a amplitude do sinal analítico (ASA).

A técnica de derivada vertical (DV) aplicada ao campo magnético anômalo realça os componentes de fontes rasas eliminando as feições de componentes mais profundas, mantendo as intermediárias (GUIMARÃES, 2009). Para melhor realce das feições magnéticas indicadas no mapa, foi utilizada técnica de sombreamento (figura 3).

A interpretação visual dos lineamentos carrega certa subjetividade, mas nada que possa comprometer o resultado final do trabalho (GUIMARÃES, 2009). Nesse sentido, visando refinar a interpretação, como citado anteriormente são utilizadas também as técnicas derivada horizontal (Figura 4) e amplitude do sinal analítico (Figura 5).

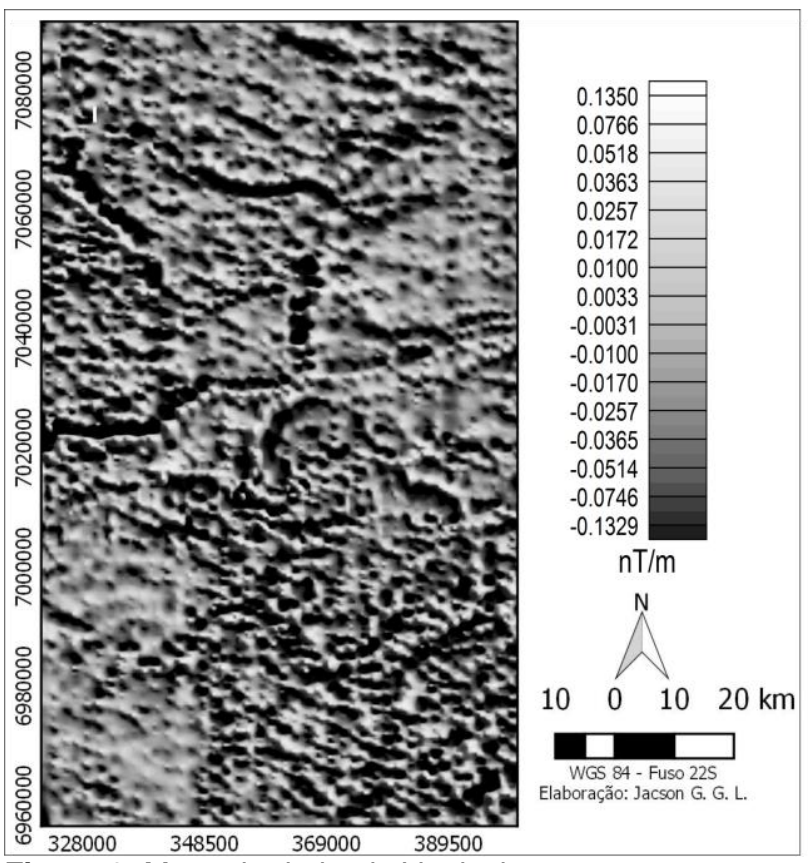

Figura 3. Mapa da derivada Vertical.

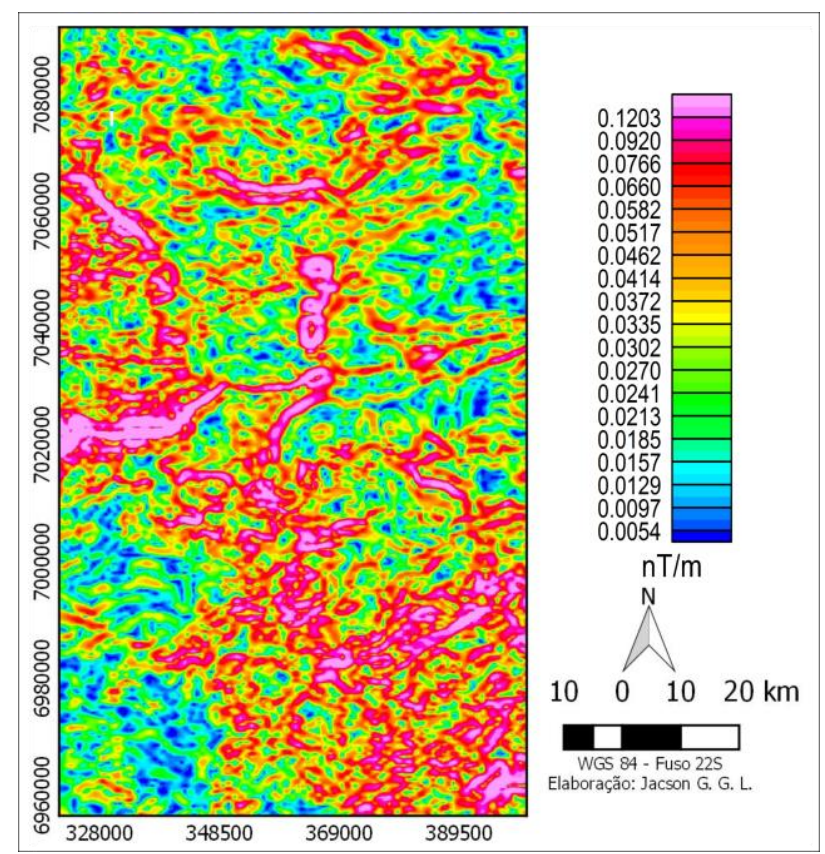

Figura 4. Mapa da derivada horizontal.

A técnica de derivada horizontal (DH), aplicada ao campo magnético anômalo, se caracteriza por gerar picos de anomalias magnéticas nas bordas dos corpos espessos, assim é também bastante utilizado para o mapeamento de corpos lineares (CORDELL; GRAUCH, 1985; MILLIGAN; GUNN, 1997).

A técnica de amplitude do sinal analítico (ASA), aplicada ao campo magnético anômalo, é uma importante ferramenta de localização das bordas de corpos que 
possuem contraste magnético, trazendo informações relevantes sobre sua geometria e quando aplicadas aos dados magnéticos de campo total anômalo. As respostas de sinal analítico ressaltam os limites na superfície dos corpos geológicos (GUIMARÃES, 2009) (figura 5).

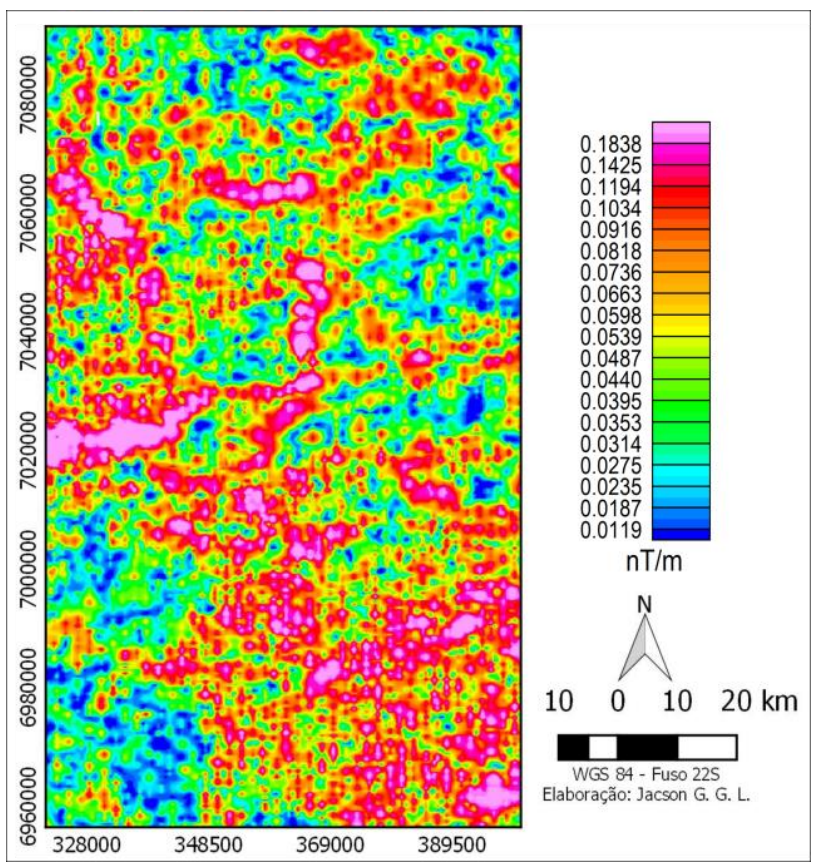

Figura 5. Mapa da amplitude do sinal analítico (ASA).

A identificação dos lineamentos geomorfológicos (positivos e negativos) foi realizada pela análise visual de imagens sombreadas. As imagens de radar SRTM-30 m foram obtidas no site do Serviço Geológico dos Estados Unidos - USGS (https://earthexplorer.usgs.gov/). Posteriormente foram convertidas, utilizando o software Quantum Gis $\AA$ versão 2.18.4, para o sistema de referência de coordenadas planas (UTM), fuso 22S, e agrupadas para constituir mosaico das cenas referentes a área de estudo. Para a análise dos lineamentos geomorfológicos, gerou-se imagem de relevo sombreado, com azimute de $45^{\circ}$ e altitude em $315^{\circ}$, como recomenda Santos et al. (2006). Posteriormente foram gerados os diagramas de rosetas dos lineamentos positivos e negativos no software Spring 5. 5. $1 \AA$.

A localização geográfica das falhas/fraturas mapeadas na área de estudo e a rede de drenagem em escala 1:100.000 foram obtidas no site da CPRM (http://geosgb.cprm.gov.br).

\section{Resultados}

A análise visual dos mapas aeromagnéticos conforme 0 descrito na metodologia resultaram no mapeamento dos lineamentos magnéticos da área de estudo (figura 6).

Analisando o gráfico de roseta de frequência absoluta percebe-se que os lineamentos magnéticos estão orientados majoritariamente para NE-SW (59\%). O trend que concentra o maior número de lineamentos (13) corresponde a orientação N70-80W, constituindo classe modal. No quadrante NE pode-se destacar as orientações entre N50-90E, que concentram 23 lineamentos (figura 6).

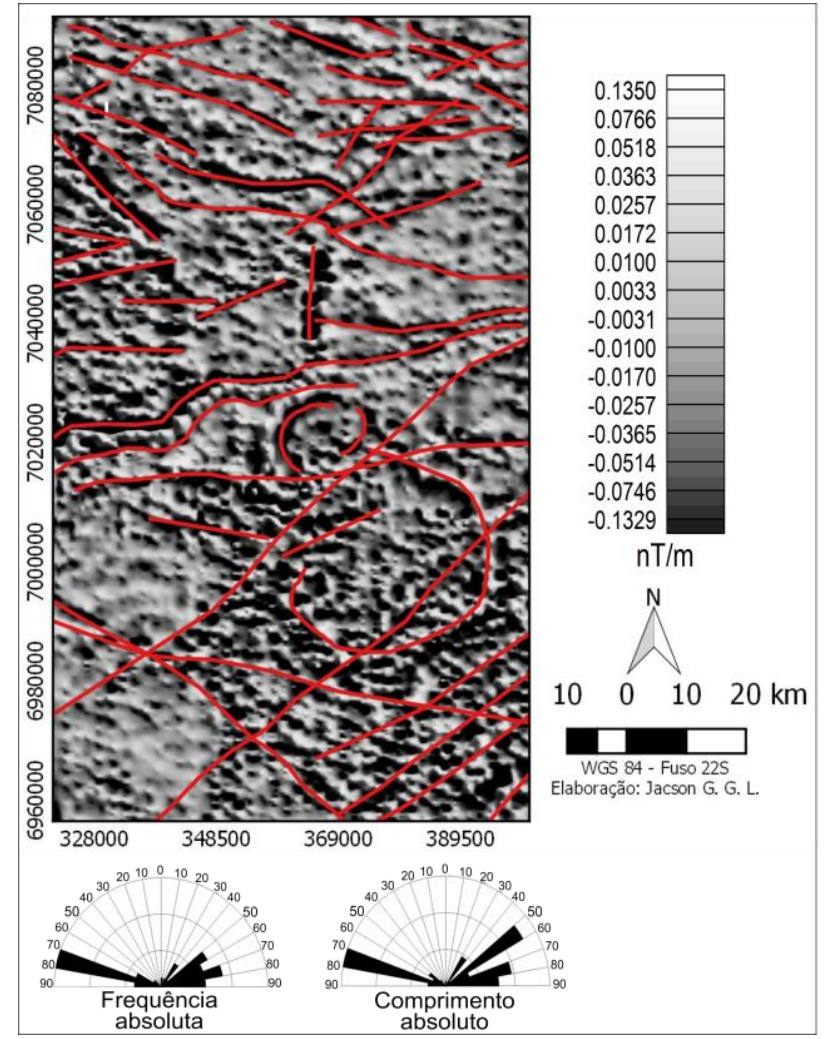

Figura 6. Mapa da derivada vertical do campo magnético total ilustrando os lineamentos magnéticos identificados.

No gráfico de comprimento absoluto o trend de maior destaque fica entre N70-80W, deve-se isso ao maior número de lineamentos com essa orientação (13) e não necessariamente ao seu comprimento (figura 6). Por outro lado o trend N50-60E que concentra 6 lineamentos também aparece com destaque no gráfico de comprimento absoluto, mostrando que apesar do menor número de lineamentos, estes apresentam maior comprimento médio. Análise mais detalhada mostra que o comprimento dos lineamentos magnéticos orientados entre N70-80W varia de $9,809 \mathrm{~km}$ a $84,800 \mathrm{~km}$, com média de 29,442 km. Já o comprimento dos lineamentos magnéticos orientados entre N 50-60 E varia de $56,99 \mathrm{~km}$ a $104,081 \mathrm{k}$, com média de $52,544 \mathrm{~km}$.

Levanto em conta o trabalho de Zalán et al (1987), percebe-se que os alinhamentos estruturais mapeados por esse autor na Bacia do Paraná apresentam boa correlação com os lineamentos magnéticos interpretados na área de estudo (figura 7).

Segundo Zalán et al. (1987) as orientações NW-SE e NESW são as mais importantes, constituindo falhas simples ou extensas zonas de falhas com centenas de quilômetros de comprimento e dezenas de quilômetros de largura. De acordo com o mesmo autor, os dois grupos de trends principais são NW-SE (N45- 65W) e NE-SW (N50-70E) e um terceiro trend, subordinado, alonga-se segundo E-W (N85-95W). 
Do total de estruturas mapeadas por Zalán et al. (1987) na Bacia do Paraná, três intersectam a área de estudo, mesmo que parcialmente, o Lineamento Taquara Verde, a Zona de Falha Lancinha/Cubatão e a Sinclinal de Torres (figura 7). Tais alinhamentos estão orientados respectivamente para E-W (N80-90E), N50-70E, N50$60 \mathrm{~W}$. Na área de estudo seis lineamentos magnéticos possuem orientação N80-90E (L15; L18; L23; L25; L39; L40), onze estão orientados entre N50-70E (L3; L19; L38; L43; L47; L48; L7; L16; L21; L41; L46) e apenas um apresenta orientação N50-60E (L45). Os lineamentos magnéticos identificados na figura 7 estão orientados principalmente entre N70-80W e N50-90E, lineamentos aproximadamente E-W são oito no total, dois (N80-90W) e seis (N80-90E). Comparando estes lineamentos com as estruturas de Zalán et al. (1987), observa-se concordância direcional entre eles (figura 7).

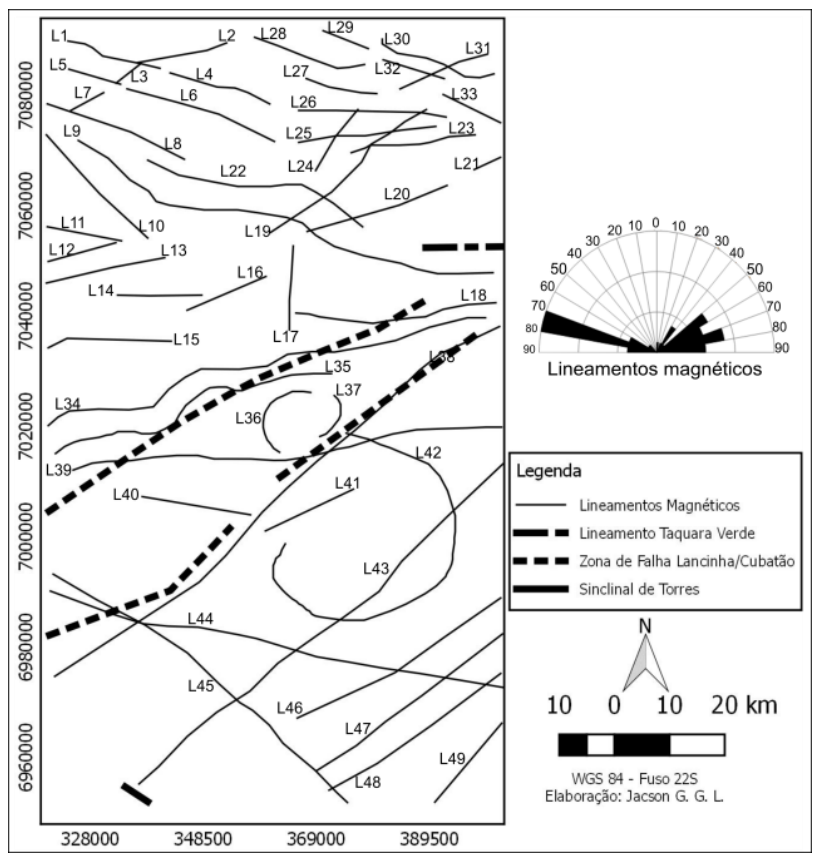

Figura 7. Mapa de lineamentos magnéticos com os lineamentos de Zalán et al. (1987) que intersectam a área de estudo.

A correlação direta entre estes lineamentos magnéticos e as estruturas de Zalán et al. (1987), reforça que as principais orientações estruturais da Bacia do Paraná são NE-SW, NW-SE e subordinadamente E-W (FULVARO et al., 1982; BELLIENI et al., 1986; SOARES, 1991; ARTUR; SOARES 2002; SOARES et al. 2007).

$\mathrm{Na}$ Figura 8 é possível observar que muitas falhas/fraturas se sobrepõem a lineamentos magnéticos ou ocorrem paralelamente. Isso pode significar que os lineamentos magnéticos correspondem a estruturas tectônicas que se estendem do embasamento até a superfície. Comparando as falhas/fraturas com os lineamentos magnéticos mapeados na área de estudo percebe-se a correlação existente entre eles.

No total são 62 falhas/fraturas na área de estudo, desse total $55 \%$ possuem orientação NW-SE e $45 \%$ orientação NE-SW. As do primeiro grupo concentram-se principalmente entre N30-60W, sendo classe modal o trend N30-40W. As do segundo grupo estão distribuídas de forma mais heterogênea, com destaque para os trends N20-30E e N60-70E (figura 8). Em contrapartida os lineamentos magnéticos estão orientados majoritariamente para NE (59\%), a orientação NW corresponde a $41 \%$. A classe modal dos lineamentos é o trend $\mathrm{N} 70-80 \mathrm{~W}$, mas a maior parte dos lineamentos estão concentrados entre N50-90E.

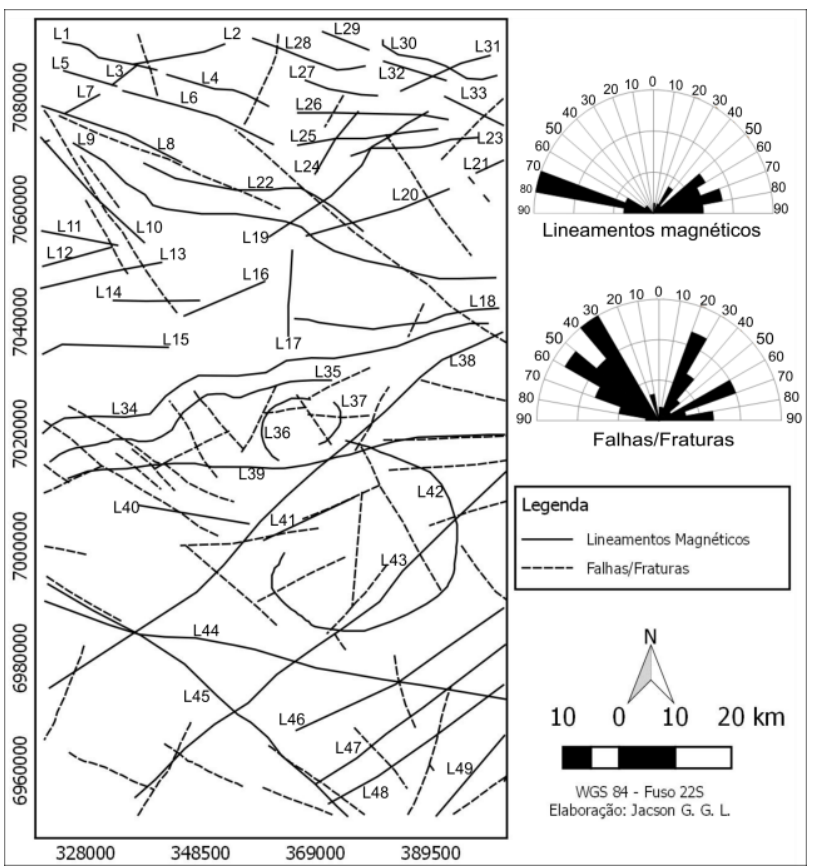

Figura 8. Mapa de lineamentos magnéticos com as falhas fraturas.

Apesar das diferenças entre os lineamentos magnéticos e as falhas/fraturas, o fato de ambos apresentarem como classe modal orientações NW, sugere que essa é a direção estrutural mais importante para a área de estudo.

Da mesma forma que as falhas/fraturas os lineamentos geomorfológicos estão orientados majoritariamente para NW (56\%) (figura 9). Estes resultados sugerem, novamente, que essa direção estrutural é a mais importante da área de estudo. Visualmente pode-se perceber a concordância direcional entre essas estruturas. Muitos lineamentos geomorfológicos se sobrepõem aos magnéticos, outros ocorrem paralelamente. Em alguns setores ocorre grande concentração de lineamentos geomorfológicos ao longo dos magnéticos. O que reforça a ideia de que os lineamentos magnéticos correspondem a estruturas tectônicas que se estendem do embasamento da Bacia do Paraná até a superfície e, sugere que essas estruturas têm papel importante na geomorfologia da área de estudo.

A importância fica mais evidente quando se analisa separadamente os lineamentos (geomorfológicos) positivos (cristas alinhadas dos divisores de água) e negativos (rios formam vales bem encaixados). Essa análise mostra que os lineamentos negativos estão orientados principalmente para NW $(60 \%)$ enquanto os lineamentos positivos estão orientados $50 \%$ para NW e $50 \%$ para NE. O fato da maior parte dos lineamentos 
negativos estarem orientados para NW sugere que os canais de drenagem estão ajustados principalmente aos lineamentos magnéticos com orientação NW-SE. O ajustamento da drenagem a estruturas de caráter regional com orientação NW-SE, já foi constatado em outros regiões do Planalto das Araucárias (LIMA; PONTELLI, 2013; SORDI et al., 2015).

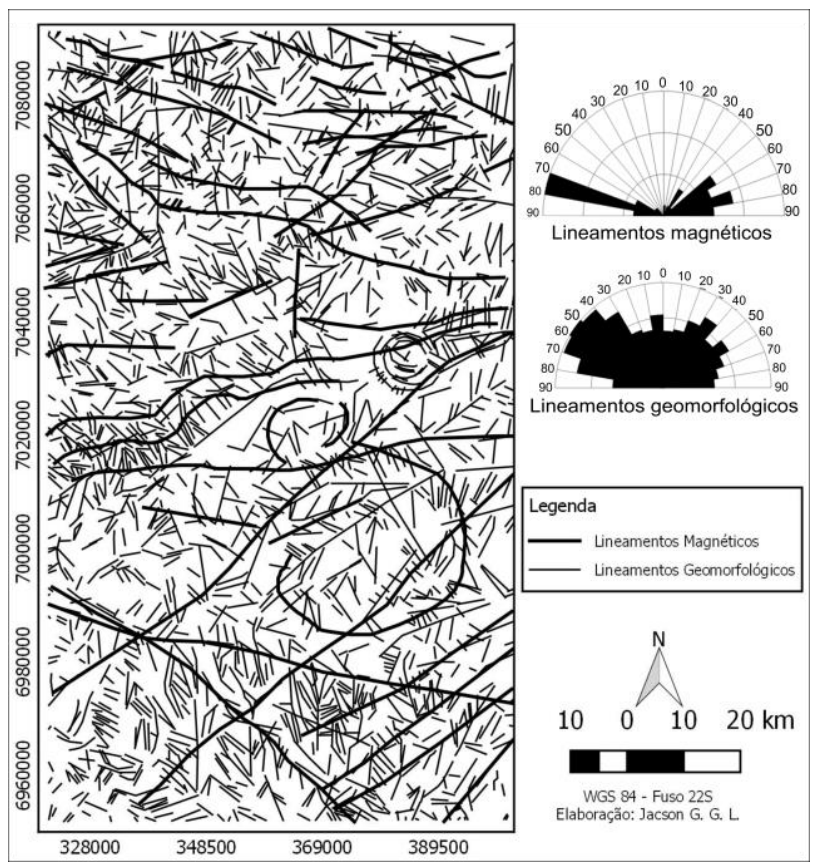

Figura 9. Mapa de lineamentos magnéticos com lineamentos geomorfológicos.

Comparando a distribuição dos lineamentos magnéticos com a distribuição dos principais rios na área de estudo percebe-se 0 ajustamento entre eles. Esse ajuste mostra que a influência estrutural pode ter sido fundamental na organização da rede de drenagem, direcionando os principais rios (figura 10).

A correlação entre estruturas tectônicas e a rede de drenagem fica evidente quando se leva em conta que os principais rios que drenam a borda leste da Bacia do Paraná estão relacionados a importantes lineamentos tectônicos, que levam o nome desses rios (FERREIRA, 1982; BELLIENI et al., 1986). Na área de estudo observase que o Rio Uruguai é correlato a um grande lineamento magnético (L44), que por analogia corresponde ao Lineamento Tectônico do Rio Uruguai (figura 10).

O terço superior do Rio Chapecó, por exemplo, está ajustado a grandes lineamentos magnéticos mapeados na área de estudo (L9; L22), o que mostra a influência estrutural nesse rio (figura 10). Esse tipo de influência já foi apontado por Fujita et al. (2017), esses autores dividiram a bacia desse rio em três compartimentos (C1; C2; C3), o C1 corresponde ao terço superior e caracteriza-se como bloco ascendente. Além disso, segundo esses autores nesse rio ocorrem numerosas cachoeiras e saltos, consideradas anomalias de $1^{\text {a }}$ ordem, que podem estar ligadas a processos neotectônicos.
Além dos rios citados acima outros importantes rios da área de estudo correlacionam-se com lineamentos magnéticos, Rio Chopim (L29; L30; L31; L32; L33), Rio Chapecozinho (L18), Rio Feliciano (L10), Rio Irani (L38; L39), rios Engano e Jacutinga (L43) (figura 10). O que indica que podem ser controlados por estruturas tectônicas.

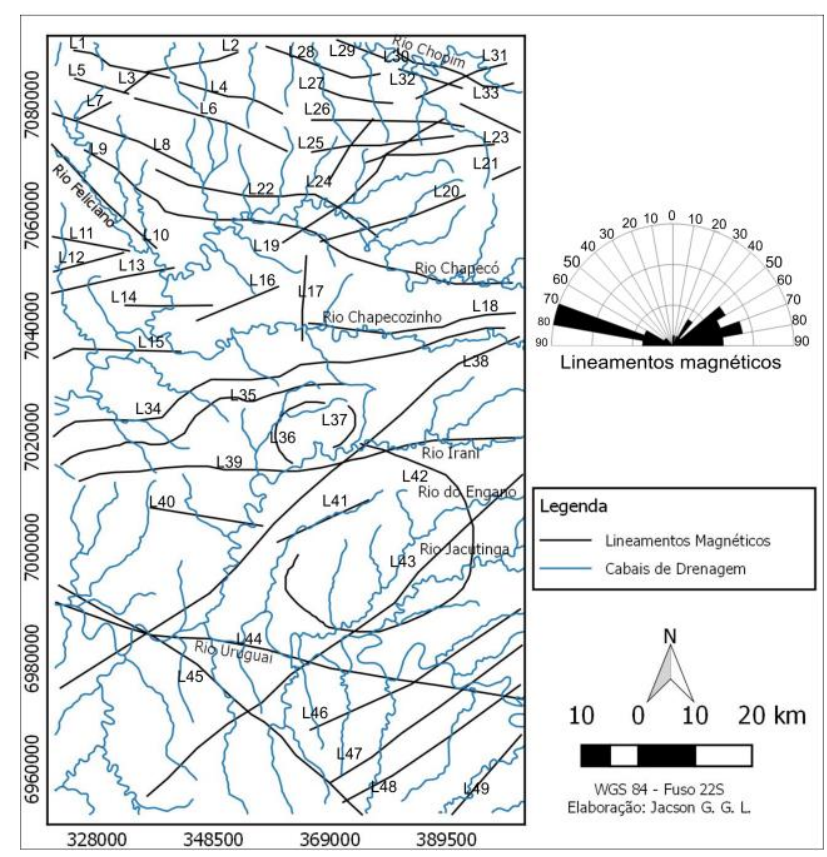

Figura 10. Mapa de lineamentos magnéticos com a drenagem.

\section{Conclusões}

As técnicas geofísicas interpretativas aplicadas ao campo magnético anômalo, (DV; DH; ASA) neste trabalho, possibilitaram o mapeamento de lineamentos magnéticos estruturais em subsuperfície e estes apresentaram boa correlação com lineamentos geomorfológicos mapeados por análise topográfica em imagens de radar SRTM-30m.

Os lineamentos magnéticos mapeados estão orientados principalmente na direções NE-SW, NW-SW e E-W. De acordo com estudos anteriores estas são as principais orientações estruturais da Bacia do Paraná. A correlação entre lineamentos magnéticos, falhas/fraturas e lineamentos geomorfológicos, mostra que as principais direções estruturais da área de estudo são NW-SE. A análise preliminar realizada entre a distribuição das estruturas mapeadas e a rede de drenagem local, sugere que a influência estrutural foi importante na organização direcional dessa rede.

\section{Agradecimentos}

Ao Instituto Federal de Santa Catarina - IFSC/SMO pela concessão de afastamento integral para realização do doutorado em Geografia no Programa de Pós-graduação da Universidade Estadual do Oeste do Paraná UNIOESTE. A Agência Nacional de Petróleo, Gás Natural e Biocombustíveis - ANP pela disponibilização dos dados aeromagnetométricos utilizados nesse trabalho. 


\section{Referências}

ARTUR, P. C.; SOAREAS, P. C. Paleoestruturas e petróleo na Bacia do Paraná, Brasil. Revista Brasileira de Geociências, São Paulo, v. 32, n. 4, p. 433-448, 2002

BELLIENI, G.; COMIN-CHIARAMONTI, P.; MARQUES, L.S.; MARTINEZ, L.A.; MELFI, A.J.; NARDY, A.J.R.; PAPATRECHAS, C.; PICCIRILLO, E.; ROISENBERG, A.; STOLFA, D. Petrogenetic aspects of acid and basaltic lavas from the Paraná plateau (Brazil): geological, mineralogical and petrochemical relationships. Journal of Petrology, v.27, p. 915-944, 1986.

CORDELL, L.; GRAUCH, V. J. S., (1985). Mapping basement magne Miller, H.G., Singh, V. (1994). Potential field tilt - a new concept for location of potential field sources. Journal of Applied Geophysics, n. 32, p. 213217.

FERREIRA, F. J. F. Integração de dados aeromagnetométricos e geológicos: configuração e evolução tectônica do Arco de Ponta Grossa. São Paulo, 1982. 169 p. Dissertação (Mestrado em Geologia) Universidade de São Paulo.

FUJITA, R.H.; PAISANI, J. C.; PONTELLI, M. E. Compartimentação fluviomorfométrica da bacia hidrográfica do rio Chapecó, primeira aproximação. Revista Brasileira de Geomorfologia, v. 18, p. 535-546, 2017.

FULVARO, V. J.; SAAD, A. R.; SANTOS, M. V.; VIANNA, R. B. Compartimentação e evolução tectônica da Bacia do Paraná. Revista Brasileira de Geociências, São Paulo, v. 12, n.4, p. 590-611, Dez. 1982.

GUIMARÃES. S. N. P. Avanços recentes na determinação das estruturas geológicas em subsuperfície da provincia uranifera Lagoa Real (BA) a partir de dados aerogeofísicos. Rio de Janeiro, 2009. 122 p. Dissertação (Mestrado em Geofísica) - Observatório Nacional/MCT.

LIMA, J. G. G.; PONTELLI, M. E. Determinantes morfoestruturais na gênese do relevo no Planalto de Palmas (PR)/Água Doce (SC) - Sul do Brasil. Revista de Geografia (UEL), Londrina, v.22, n.3. p. 81-92, 2013.

MILLIGAN P.R. \& GUNN P.J. Enhancement and presentation of airborne geophysical data. Journal of Australian Geology \& Geophysics. n. 17, v.2, p. 63-75, 1997.

SAADI, A. Modelos morfogenéticos e tectônica global: reflexões conciliatórias. Geonomos, Belo Horizonte, v. 6, n. 2, p. 55-63, 1998.

SANTOS, J. C.; OKA-FIORI, C.; CANALI, N. E.; FIORI, A. P.; SILVEIRA, C. T.; SILVA, J. M. F.; ROSS, J. L. S. Mapeamento geomorfológico do estado do Paraná. Revista Brasileira de Geomorfologia, Brasília, ano 7, n. 2, p. 3-12, 2006.

SOARES, P. C. Tectônica sinsedimentar cíclica na Bacia do Paraná: controles. Curitiba, 1991. 142 p. Tese para concurso ao cargo de professor Titular no Departamento de Geologia da Universidade Federal do Paraná.
SOARES, A. P.; SOARES, P. C.; BETTÚ, D. F.; HOLZ, D. F. Compartimentação estrutural da Bacia do Paraná: a questão dos lineamentos e sua influência na distribuição do sistema Aquífero Guarani. Geociências, UNESPE, São Paulo, v. 26, n. 4, p. 297-311, 2007.

SORDI, M. V.; SALGADO, A. A. R.; PAISANI, J. C. Evolução do relevo em áreas de tríplice divisor de águas regional - o caso do Planalto de Santa Catarina: uma análise morfoestrutural. Revista Brasileira de Geomorfologia, São Paulo, v. 16, ํํ 4, 2015.

ZALÁN, P. V.; WOLFF, S.; CONCEIÇÃO, J. C. J.; ASTOLFI, M. A. M.; VIEIRA, I. S.; APPI, V. T.; ZANOTTO, O. A. Tectônica e sedimentação da Bacia do Paraná. In: III Simpósio Sul-Brasileiro de Geologia, 1987, Curitiba. Anais... Curitiba: Sociedade Brasileira de Geologia, v. 1, 1987, p. 441-477. 